\title{
Study of Blending Mechanism of Bio-Binder and Petroleum Asphalt
}

\author{
Jin Xi \\ Roads and Material Center \\ Jiangxi Transportation Institute \\ Nanchang, China \\ 32277794@qq.com \\ Xilan Yu \\ Roads and Material Center \\ Jiangxi Transportation Institute \\ Nanchang, China \\ 444581795@qq.com
}

\author{
Yaoting Zhu \\ Roads and Material Center \\ Jiangxi Transportation Institute \\ Nanchang, China \\ 329560032@qq.com
}

\author{
Renhui Wang \\ National Engineering Laboratory for Advanced Road \\ Materials \\ Jiangsu Transportation Institute \\ Nanjing, China \\ wrh007@jsti.com
}

\begin{abstract}
In order to explore the blending mechanism of biobinder and petroleum asphalt, this paper used high shear equipment to mix them, with varying conditions of temperature $\left(130 \sim 145^{\circ} \mathrm{C}, 145 \sim 160^{\circ} \mathrm{C}, 160 \sim 175^{\circ} \mathrm{C}, 175 \sim\right.$ $\left.190^{\circ} \mathrm{C}\right)$, speed (500r, 1000r, 2000r, 3000r) and mixing time (15min, 30min, 45min, 60min). Low speed agitation was later applied to fully develop the mixture, until the bubbles disappeared and the final products were formed. Needle penetration and ductility tests were used to assess the variation pattern with the different conditions. The findings are: (1) higher blending temperature caused more severe aging, showing declining needle penetration and ductility values; (2) with longer blending time, the mixture became more homogeneous; however, too long mixing also meant continuous heating, giving rise to certain degree of aging. (3) low blending speed was not sufficient to achieve a totally uniform mixture while higher speed showed better results.
\end{abstract}

Keywords: bio-binder; mixture; blending temperature; blending time; blending speed

\section{INTRODUCTION}

With the rapid growth of China's economy, a lot of road construction is taking place, leading to the increasing demand for petroleum asphalt material. Petroleum asphalt is produced from oil, and oil is a nonrenewable resource, facing the problem of resource depletion hence very unfavorable for the development of the transport industry. Bio-binder is a new material that can solve the issue of insufficient supply of petroleum asphalt by reducing its consumption. It mainly comes from waste biomass and possesses the features of environmental-friendliness and inexhaustible supply [1]. There are three major options of applying bio-binder in road engineering, i.e. directly replacing petroleum asphalt (100\%), partially replacing to serve as a diluent (25-75\%) and petroleum asphalt modifier $(<10 \%)$ [2,3,4]. Although bio-binder material does have some degree of mechanical strength, the common asphalt property tests reveal that it cannot meet certain road performance requirements. Usually it cannot directly replace petroleum asphalt, but is blended together as an additive. Because there are differences in the compositions and sources of bio-binder and petroleum asphalt, the research in the blending mechanism of the two is necessary while not enough $[5,6,7,8]$.

In order to explore the blending mechanism of biobinder material with petroleum asphalt, this paper used high shear equipment for their first-step mixing, with the varying conditions of temperature $\left(130 \sim 145^{\circ} \mathrm{C}, 145 \sim\right.$ $160^{\circ} \mathrm{C}, 160 \sim 175^{\circ} \mathrm{C}, 175 \sim 190^{\circ} \mathrm{C}$ ), speed (500r, 1000r, 2000r, 3000r) and mixing time (15min, 30min, 45min, $60 \mathrm{~min}$ ). After this, low speed agitation was applied to fully develop the mixture, until the bubbles disappeared to obtain the final products. Needle penetration and ductility tests were then used to assess the variation pattern of the products with different conditions.

\section{RAW MATERIALS}

\section{A. Bio-binder}

The bio-binder this paper used was from a biotech company in Wenzhou China, the raw material of which were cottonseed and soybeans; it was produced using the oil extraction remaining of them which then underwent a process of distillation, oxidation, etc. to achieve the final product i.e. the bio-binder $[9,10]$. The properties of the bio-binder were evaluated by the asphalt binder evaluation methods, and the results are shown in Table 1. 
TABLE I.

THE TECHNICAL INDICATOR OF BIO-BINDER

\begin{tabular}{|c|c|c|}
\hline Item & Unit & Bio-binder \\
\hline Needle penetration $\left(5^{\circ} \mathrm{C}, 100 \mathrm{~g}, 5 \mathrm{~s}\right)$ & $0.1 \mathrm{~mm}$ & 62.9 \\
\hline Needle penetration $\left(10^{\circ} \mathrm{C}, 100 \mathrm{~g}, 5 \mathrm{~s}\right)$ & $0.1 \mathrm{~mm}$ & 81.5 \\
\hline Needle penetration $\left(15^{\circ} \mathrm{C}, 100 \mathrm{~g}, 5 \mathrm{~s}\right)$ & $0.1 \mathrm{~mm}$ & 121.0 \\
\hline Needle penetration $\left(20^{\circ} \mathrm{C}, 100 \mathrm{~g}, 5 \mathrm{~s}\right)$ & $0.1 \mathrm{~mm}$ & 163.9 \\
\hline Needle penetration $\left(25^{\circ} \mathrm{C}, 100 \mathrm{~g}, 5 \mathrm{~s}\right)$ & $0.1 \mathrm{~mm}$ & 223.3 \\
\hline Penetration Index (PI) & - & 2.48 \\
\hline Softening point & ${ }^{\circ} \mathrm{C}$ & 35.9 \\
\hline Ductility $\left(5 \mathrm{~cm} / \mathrm{min}, 15^{\circ} \mathrm{C}\right)$ & $\mathrm{cm}$ & $>100$ \\
\hline Ductility $\left(5 \mathrm{~cm} / \mathrm{min}, 10^{\circ} \mathrm{C}\right)$ & $\mathrm{cm}$ & $>100$ \\
\hline Ductility $\left(5 \mathrm{~cm} / \mathrm{min}, 5^{\circ} \mathrm{C}\right)$ & $\mathrm{cm}$ & $>100$ \\
\hline Solubility (Trichloroethylene) & $\%$ & 49.75 \\
\hline \multicolumn{3}{|c|}{ Thin-film oven test $\left(163^{\circ} \mathrm{C}, 5 \mathrm{~h}\right)$} \\
\hline Mass loss & $\%$ & -0.64 \\
\hline Penetration ratio $\left(25^{\circ} \mathrm{C}\right)$ & $\%$ & 48.62 \\
\hline Ductility $\left(5 \mathrm{~cm} / \mathrm{min}, 15^{\circ} \mathrm{C}\right)$ & $\mathrm{cm}$ & 77.5 \\
\hline
\end{tabular}

As can be seen from Table 1, the bio-binder had a needle penetration of above $200(0.1 \mathrm{~mm})$ at $25^{\circ} \mathrm{C}$, more than 2 to 3 times that of the conventional petroleum asphalt; the penetration index result indicated the temperature sensitivity of bio-binder was not high; its softening point was lower than that of ordinary asphalt; in addition, due to the differences in the compositions, its solubility was also lower compared to ordinary asphalt; but bio-binder showed good extensibility at $5^{\circ} \mathrm{C}, 10^{\circ} \mathrm{C}$ and $15^{\circ} \mathrm{C}$ with a ductility value larger than $100 \mathrm{~cm}$; its properties declined a lot after aging, probably because the relatively high percentage of volatile contents suffered a high degree of mass loss during aging.

\section{B. Base asphalt}

The base asphalt used in this paper was AH-50 heavy traffic base asphalt, with the technical indicator shown in Table 2.

TABLE II. MAIN TECHNICAL INDICATOR OF AH-50 ASPHALT

\begin{tabular}{|l|l|l|}
\hline \multicolumn{1}{|c|}{ Item } & \multicolumn{1}{c|}{ Unit } & AH-50 Asphalt \\
\hline Needle penetration $\left(25^{\circ} \mathrm{C}, 100 \mathrm{~g}, 5 \mathrm{~s}\right)$ & $0.1 \mathrm{~mm}$ & 59 \\
\hline Softening point & ${ }^{\circ} \mathrm{C}$ & 48.0 \\
\hline Ductility $\left(5 \mathrm{~cm} / \mathrm{min}, 15^{\circ} \mathrm{C}\right)$ & $\mathrm{cm}$ & $>100$ \\
\hline Ductility $\left(5 \mathrm{~cm} / \mathrm{min}, 10^{\circ} \mathrm{C}\right)$ & $\mathrm{cm}$ & 16.97 \\
\hline Ductility $\left(5 \mathrm{~cm} / \mathrm{min}, 5^{\circ} \mathrm{C}\right)$ & $\mathrm{cm}$ & Brittle failure \\
\hline
\end{tabular}

\section{PRODUCTION METHOD AND PRODUCT EVALUATION}

\section{A. Conditions of production}

The detailed process was that the asphalt was firstly melted, and then added with $25 \%$ of bio-binder by highspeed shear emulsification machine rotating at different speed (500r, 1000r, 2000r, 3000r) for different length of time (15min, 30min, 45min, 60min) at different temperature $\quad\left(130 \sim 145^{\circ} \mathrm{C}, \quad 145 \sim 160^{\circ} \mathrm{C}, \quad 160 \sim 175^{\circ} \mathrm{C}\right.$, $175 \sim 190^{\circ} \mathrm{C}$ ). The thus obtained mixture was then agitated at low speed and left over till the bubbles disappeared to fully develop its properties and turn itself into the final bioasphalt binder.

This paper took needle penetration and ductility as the main indicators to study the bio-asphalt binder material generated under different blending conditions.

\section{B. Properties evaluation}

This paper took needle penetration and ductility as the main indicators to study the bio-asphalt binder material generated under different blending conditions.

\section{RESULTS AND ANALYSIS}

\section{A. The effect of varying blending temperature}

With the other experimental conditions kept the same, the variation pattern of bio-asphalt binder properties along with the changing blending temperature is shown in Figure 1 and 2.

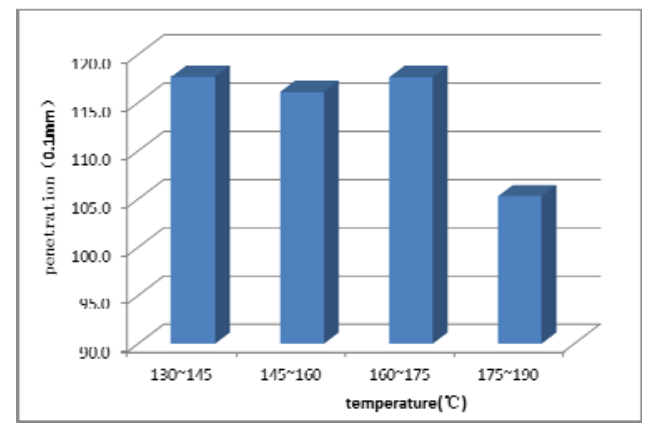

Figure 1. The needle penetration at different temperature.

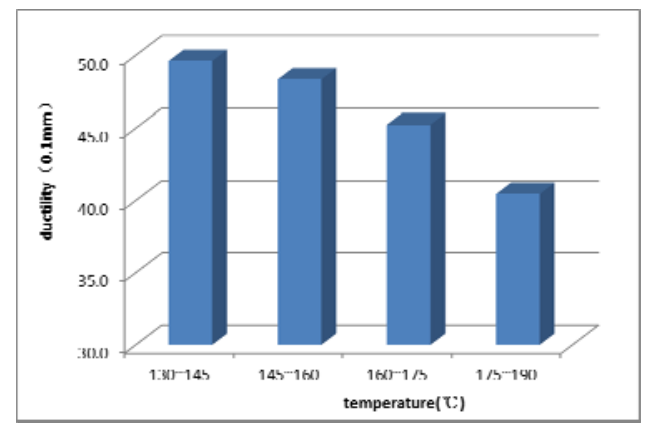

Figure 2. The ductility at different temperature.

It can be seen in Figure 1 and 2 that as the temperature increases, the needle penetration values of bio-asphalt binder were almost the same till $175 \sim 190^{\circ} \mathrm{C}$ when the reduction became more obvious; whereas the ductility kept decreasing with increasing temperature. The main reason for the above phenomenon is the higher temperature 
caused more severe aging, reflected as smaller penetration and ductility values.

\section{B. The effect of varying blending time}

With the other experimental conditions kept the same, the variation pattern of bio-asphalt binder properties along with the changing blending time is shown in Figure 3 and 4.

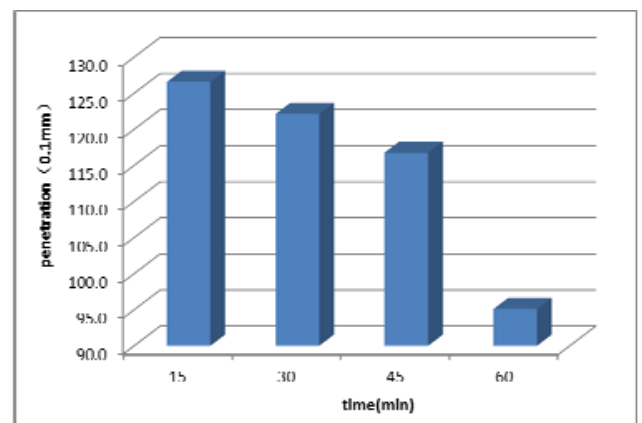

Figure 3. The needle penetration at different blending time.

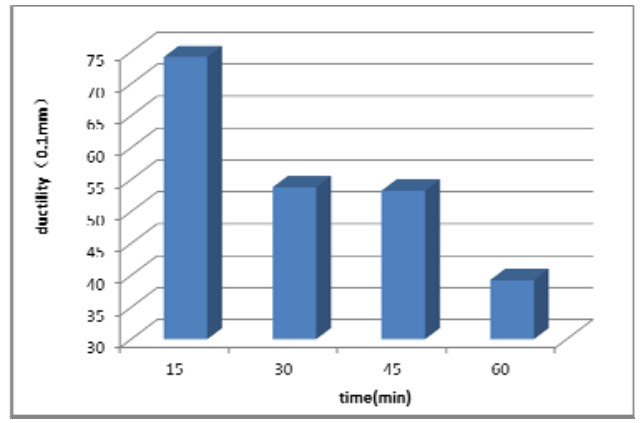

Figure 4. The ductility at different blending time.

Figure 3 and 4 indicated that with the increasing blending time, the needle penetration of bio-asphalt binder kept declining, especially when the 60min of mixing time was reached; similar decreasing trend was shown in ductility, especially in $15 \mathrm{~min}$ to $30 \mathrm{~min}$, and $45 \mathrm{~min}$ to $60 \mathrm{~min}$ when stepwise reduction occurred. The main reason for the above is that as the mixture was mixed for longer time, it became more homogeneous; however, too long mixing also meant continuous heating, giving rise to a certain degree of aging.

\section{The effect of varying blending speed}

With the other experimental conditions kept the same, the variation pattern of bio-asphalt binder properties along with the changing blending speed is shown in Figure 5 and 6.

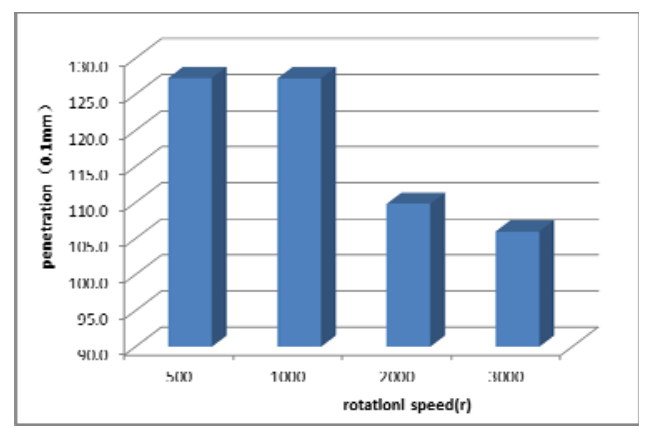

Figure 5. The needle penetration at different rotation speed.

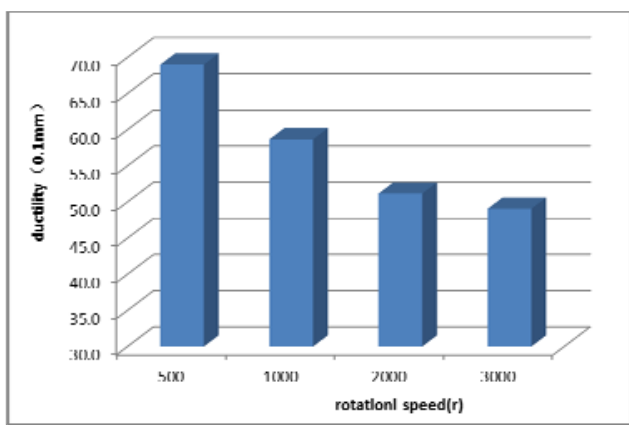

Figure 6. The ductility at different rotation speed.

As shown in Figure 5 and 6, at low blending speed of 500r and 1000r, the penetration value of bio-asphalt binder was almost constant; only when the speed was further increased to 2000r, a big reduction was seen and from 2000r to 3000r, the penetration value of the mixture was again reduced, but to a less degree. In the case of ductility, it was showing a continued downward trend; when the speed was high, the trend slowed down. The main reason for the above is that lower speed was not sufficient to achieve a totally uniform mixture while a higher speed gave better results.

\section{CONCLUSIONS}

(1) The bio-binder this paper used had a needle penetration of more than 2 to 3 times that of the conventional petroleum asphalt at $25^{\circ} \mathrm{C}$; the penetration index result indicated its temperature sensitivity was not high; its softening point was lower; in addition, due to the differences in the compositions, its solubility was also lower; but bio-binder showed good extensibility at $5^{\circ} \mathrm{C}$, $10^{\circ} \mathrm{C}$ and $15^{\circ} \mathrm{C}$ with a ductility value larger than $100 \mathrm{~cm}$; its properties declined a lot after aging, probably because the relatively high percentage of volatile contents suffered a high degree of mass loss during aging.

(2) With the other experimental conditions the same, as temperature increased, the bio-asphalt binder was more vulnerable to aging. The mixture showed relatively small difference in needle penetration when temperature changed in the range of $130 \sim 145^{\circ} \mathrm{C}, 145 \sim 160^{\circ} \mathrm{C}$ to $160 \sim 175^{\circ} \mathrm{C}$, only more significant when $175 \sim 190^{\circ} \mathrm{C}$ was reached, whereas for ductility, when temperature increased, it kept on decreasing.

(3) If other experimental conditions were the same, with the increasing blending time, the mixture became more homogeneous; however, too long mixing also meant continuous heating, giving rise to a certain degree of aging.

(4) With the other experimental conditions the same, due to the reason that lower speed was not sufficient to achieve a totally uniform mixture while a higher speed would give better results, at low blending speed of 500r and 1000r, the penetration value of bio-asphalt binder was almost constant; only when the speed was further increased to 2000r, a big reduction was seen and from 2000r to 3000r, the penetration value of the mixture was again reduced, but to a less degree. In the case of ductility, it was showing a continued downward trend; when the speed was high, the trend slowed down. 


\section{ACKNOWLEDGEMENT}

This work was financially supported by the Construction Science Research Program of Ministry of Transport (2013318780290), Science Research Program of Jiangxi Provincial Department of Transportation (2011H0022) and National Engineering Laboratory for Advanced Road Materials Public Project Program.

\section{REFERENCES}

[1] Mills-Beale J., Fini E., Goh S. W., et al. State of the art in sustainable asphalt pavement materials [C]. Proceedings of International Workshop on Energy and Environment in the Development of Sustainable Asphalt Pavements, 2010, 109-113.

[2] Raouf A. M., Williams R. C. Determination of pre-treatment procedure required for developing bio-binders from bio-oils [C]. Proceedings of 2009 Mid-Continent Transportation Research Symposium, Ames, Iowa, 2009.

[3] M. Lei, Y. Zhu, M. Peng. Study on Physical and Chemical Properties of Bio-Binder [J]. Journal of China \& Foreign Highway, 2012, 32(1): 222-225.

[4] McCready N. S., Williams R. C. Utilization of biofuel coproducts as performance enhancer in asphalt binder [J] Transportation Research Record, 2008, 2051: 8-14.
[5] D. Cao, H. Zhang, M. He, X. Wu, X. Tang. The production method and application of modified bio-asphalt, bio-asphalt mixture [P]. Chinese patent CN 10276630 A, 2012-11-07.

[6] Raouf A. M., Williams R. C. General physical and chemical properties of bio-binders derived from fast pyrolysis bio-oils [C]. Proceedings of 2009 Mid-Continent Transportation Research Symposium, Ames, Iowa, 2009.

[7] Mohamed Abdel Raouf, R. Christopher Williams. Determination of Pre-Treatment Procedure Required for Developing Bio-Binders from Bio-Oils [S]. Proceedings of the 2009 Mid-Continent Transportation Research Symposium, Ames, Iowa, August 2009.

[8] Sheng Tang, R. Christopher Williams. Antioxidant Effect of BioOil Additive ESP on Asphalt Binder [J]. Proceedings of the 2009 Mid-Continent Transportation Research Symposium, Ames, Iowa, August 2009.

[9] Ronald Christopher WILLIAMS, Mohamed Abdel Raouf MOHAMD METWALLY, Robert C. Brown. Bio-oil formulation as an asphalt substitute: United States, US 2011/0294927 A1 [P].Dec.1, 2011.

[10] Ronald Christopher WILLIAMS, Robert C. Brown, Sheng TANG. Asphalt Materials containing Bio-oil and Methods for Production Thereof. United States, US 2010/0275817 A1[P].Nov.4,2010. 